Int. J. Dev. Biol. 49: 143-150 (2005)

doi: $10.1387 / \mathrm{ijdb} .041935 \mathrm{ab}$

\title{
Migration of neural crest-derived enteric nervous system precursor cells to and within the gastrointestinal tract
}

\author{
ALAN J. BURNS* \\ Neural Development Unit, Institute of Child Health, University College London, London, UK
}

\begin{abstract}
The enteric nervous system, the intrinsic innervation of the gastrointestinal tract, consists of large numbers of phenotypically diverse neurons and glial cells, arranged in complex interconnecting plexuses situated between the smooth muscle layers of the gut wall. Recently, the enteric nervous system has attracted much attention from developmental biologists whose efforts have focused on analysing the cellular origins of enteric nervous system precursor cells, how these cells migrate to and within the gut and the identification of signalling mechanisms which cause migrating cells to differentiate into the appropriate phenotypes in the appropriate locations. This review summarises the state of knowledge concerning the early stages of enteric nervous system development and concentrates on: (i) the embryological origins of the neural crest cells which colonise the gastrointestinal tract, (ii) their spatiotemporal migration within the gut, (iii) the possible pre-specification of neural crest cells as enteric nervous system precursors and (iv) factors influencing their directional migration within the gut.
\end{abstract}

KEY WORDS: enteric nervous system, neural crest cell, migration, colonisation, gut

\section{Introduction}

The enteric nervous system (ENS), the intrinsic innervation of the gastrointestinal tract, consists of large numbers of phenotypically diverse neurons and glial cells, that are arranged in complex interconnecting plexuses situated between the smooth muscle layers of the gut wall. The function of the ENS is to regulate gut processes that include complex propulsive motor activity (such as peristalsis and migrating motor complexes), secretion and absorption, blood flow and modulation of immune and endocrine functions. Unlike the innervation of other organs, the ENS is capable of mediating reflex activity in the absence of input from the brain or spinal cord, due to the presence of motor circuits that consist of sensory neurons, intrinsic primary afferent neurons, interneurons and excitatory and inhibitory motorneurons (Costa et al., 2000, Furness, 2000; Furness and Costa, 1987). The ENS has recently attracted much attention from scientists in a range of disciplines including neuroscience, gastroenterology, pathology and not least in developmental biology. Indeed, it has been the efforts to analyse the cellular origins of ENS cells, how these cells migrate to and within the gut and the identification of signalling mechanisms that cause migrating cells to differentiate into the appropriate phenotypes in the appropriate locations, that have greatly advanced the field of ENS development in recent years. This review summarises the state of knowledge concerning the early stages of ENS development and concentrates on the embryological origins and pathways of migration of the neural crest cells (NCC) that form the ENS. Major advances in these areas have been achieved in the laboratory of Nicole Le Douarin over a period of time exceeding 30 years (Le Douarin and Kalcheim, 1999).

\section{Enteric nervous system precursor cells are derived from the neural crest}

Although Yntema and Hammond (Yntema and Hammond, 1954) investigated the ontogeny of the ENS over fifty years ago and determined, using neural tube ablation studies, that its precursors are derived from rhombencephalic (vagal) NCC, it was the pioneering work of Le Douarin and colleagues almost twenty years later that established the precise axial origin of the NCC populations that form the ENS. Using the novel quail-chick interspecies grafting technique (Le Douarin, 1969), sections of neural tube (and neural crest) were isotopically transplanted from quail to chick embryos at the same stages of development. Subsequent analysis of the developing gut for the presence of quail cells within the enteric

Abbreviations used in this paper: CAM, chick chorioallantoic membrane; CM, circular muscle; DCC, deleted in colorectal cancer; ENS, enteric nervous system; MYP, myenteric plexus; NCC, neural crest cell; NT, neural tube; SMP, submucosal plexus. 
plexuses allowed the origin of ENS cells to be defined to the vagal region of the neural crest, adjacent to somites 1-7, which populates the entire length of the gut, while a second region of the neuraxis, the sacral neural crest, caudal to the $28^{\text {th }}$ pair of somites, was also shown to contribute cells to the hindgut (Le Douarin and Teillet, 1973, Le Douarin and Teillet, 1974). Although numerous authors have subsequently supported the data concerning the contribution of the vagal NC (Burns et al., 2000, Durbec et al., 1996, Epstein et al., 1994), due to conflicting findings, the precise role of the sacral neural crest in ENS formation remained controversial for many years. Evidence supporting a role for sacral NCC in ENS development came from cell labelling studies that traced the development of sacral NCC in the chick using a monoclonal antibody (NC-1) that binds to migrating NCC (Pomeranz and Gershon, 1990). These authors reported streams of immunopositive cells in the dorsal bowel by embryonic day (E)4, within the mesentery at E5, giving rise to the nerve of Remak, (a nerve particular to avians which is located external to the gut and considered part of the parasympathetic nervous system) and that eventually encircled the hindgut. Since vagal NCC had not colonised the hindgut at these stages of development, it was inferred that the streams of labelled cells were derived from the sacral crest. Similar observations were made in cell tracing studies performed in the chick (Pomeranz et al., 1991, Serbedzija et al., 1991) and mouse gut (Serbedzija et al., 1991) using injection of the cell tracers, Dil and/or a replicationdeficient retrovirus. In these investigations, labelled cells were reported in the hindgut mesenchyme by E4 in the chick and beginning at E9.5 in the mouse i.e. well before the arrival of vagalderived cells in the caudal gut regions. However, in contrast to the observations reporting the early arrival of sacral NCC within the gut (Pomeranz and Gershon, 1990; Pomeranz etal., 1991; Serbedzija, 1991), studies using gut explant cultures failed to identify an early migrating sacral NC-derived contribution to the ENS. When segments of hindgut were removed and cultured, prior to the arrival of vagal NCC, enteric neurons were not found to develop in the cultured explants (Allan and Newgreen, 1980, Kapur et al., 1992, Nishijima etal., 1990). Similarly, in midgut transection experiments, when the bowel was severed in ovo prior to the arrival of the rostrocaudally migrating vagal NCC (Meijers et al., 1989), the hindgut remained aganglionic, suggesting there was no contribution to the hindgut from the sacral crest. More recently, Young et al., (Young et al., 1998), using detailed immunohistochemical labelling of migrating NCC, described the rostro-caudal progression of vagal-derived enteric precursors along the gut. In their studies, a caudorostral progression of ENS precursors that could be attributed to early migrating sacral NCC was not observed. The conclusions from these investigations were either that sacral NCC do not contribute to the ENS, or if they do colonise the hindgut, then sacral cells either fail to be detected by, or show delayed expression of all the conventional markers that reliably labelled migrating vagal NCC (Young et al., 1998). A further possibility is that in order to colonise the hindgut, or to produce neuronal characteristics, sacral NCC may require the presence of vagal crest-derived cells within the hindgut. Therefore, if the gut was removed and cultured before the arrival of vagal NCC, or if their arrival within the hindgut was prevented by severing the bowel, any sacral NCC already present within the bowel could not develop due to the absence of vagal NCC-derived cells, or of factors, or signalling molecules, released by them or their progeny.
It is difficult to explain the discrepancies between the findings of these experiments, where one set of results describes the early migration of sacral NCC into the hindgut, whereas the other presents evidence to the contrary. However, like most experimental procedures, there are limitations to each approach that may, in part, account for the different findings. One potential weakness of the sacral NCC studies, such as those of Pomeranz et al. (Pomeranz et al., 1991) and Serbedzija et al. (Serbedzija et al., 1991) using injection of either the vital fluorescent dye, Dil or the replication-deficient retrovirus $L Z 10$, is that although some crest cells appear to have been labelled, it is possible that other germ layers were also labelled at the time of injection. In both of these studies, in addition to presumptive ENS ganglion cells, cells within the gut mesenchyme and epithelium were also positively marked. Further, due to technical difficulties, the cellular fates of labelled cells were not determined within the hindgut. In combination, the presence of unidentified positively stained cells, in areas other than presumptive enteric ganglia, caused difficulty in the interpretation of the findings. Similarly, Pomeranz and Gershon, (Pomeranz and Gershon, 1990), who employed the antibody NC1 to label migrating NCC, described a caudal stream of positive cells encircling the gut at E5, that was attributed to being sacral $\mathrm{NC}$ in origin. However, it is possible that these cells were not NCC and were of mesenchymal in origin since; 1 ) these cells were not shown to co-express neuronal markers, 2) NC-1 is not entirely neural crest specific as the epitope is associated with several high-molecular-weight polypeptides (Vincent and Thiery, 1984).

\section{Sacral NCC colonise the hindgut after it has been colonised by vagal NCC}

Clearly, without a means of selectively labelling sacral NCC, that could be used in conjunction with techniques such as immunohistochemistry to identify enteric neuronal and glial phenotypes, reliable tracing of sacral NCC development proved to be difficult. In addition, without specifically labelling this subpopulation, if sacral NCC colonised the gut after the arrival of vagal cells then their presence within the hindgut would be "masked" by the earlier arriving vagal-derived cells, thus making their detection impossible. These problems were overcome in a series of more recent studies initiated in the laboratory of Nicole Le Douarin, utilising quail-chick interspecies grafting to selectively label sub-populations of NCC, in conjunction with antibody doublelabelling to identify quail cells and neuronal and glial phenotypes within chick enteric ganglia. The combination of these techniques allowed the spatiotemporal migration pathways of vagal and sacral NCC to be determined, along with the identification of the subsequent phenotypes of crest-derived cells within the gut (Burns et al., 2000, Burns and Le Douarin, 1998; Burns and Le Douarin, 2001). These studies demonstrated that vagal NCC initially accumulated in the caudal branchial arches, then entered the foregut mesenchyme at E3 and migrated in a rostro-caudal direction, colonising the hindgut during E7-9. Sacral NCC were found to initially congregate in the dorsal wall of the hindgut where they formed the nerve of Remak at E3.5. Sacral NCC resided in the nerve of Remak until E7, when nerve fibres project into the hindgut, then migrated into the gut along these nerve fibres, colonising the hindgut in larger numbers from E10. These findings clearly demonstrated that sacral NCC colonise the hindgut 2-3 
days after it had been colonised by vagal NCC. This delayed migration and proliferation of sacral NCC in the hindgut seemed to support the idea that sacral crest-derived cells required the presence of factors or signalling molecules released by vagalderived cells or their progeny in order to colonise the hindgut. However, when the vagal crest was ablated, thus preventing vagal-derived NCC from migrating into the gut and eventually colonising the hindgut (Burns et al., 2000), sacral cells colonised the gut and differentiated in an apparently normal manner, thus demonstrating that in order to contribute to the ENS, sacral NCC do not require an interaction with vagal-derived cells. The studies of Burns et al., (Burns et al., 2000, Burns and Le Douarin, 1998) therefore demonstrated that sacral NCC migrate into the hindgut independently of vagal NCC, later in development and differentiate into neurons and glia. Although sacral NCC were found within the entire post-umbilical gut, their contribution was mainly confined to the terminal hindgut, where they comprised up to $17 \%$ of enteric neurons (Burns and Le Douarin, 1998). Supporting evidence for this later arrival of sacral NCC into the hindgut has also been obtained in the mouse embryo (Kapur, 2000). Using Wnt1-lacZ transgene expression as an early marker of murine NCC, this author described the early colonisation of the pelvic ganglia in the mesenchyme surrounding the hindgut while the gut appeared to remain free of labelled cells prior to the arrival of vagal-derived enteric precursors. Further, when early vagal NCC-free hindgut was removed and cultured under the mouse kidney capsule, neurons failed to develop in the explant, indicating that early migrating sacral-derived cells are not present in the hindgut prior to vagal cells. These findings support those of Burns and Le Douarin (Burns and Le Douarin, 1998), where sacral NCC initially colonise the extramural ganglia (i.e. the nerve of Remak in the chick; the pelvic ganglia in the mouse) and secondarily enter the hindgut after it has been colonised by vagal NCC.

\section{Spatiotemporal migration of NCC within the gut}

Quail-chick interspecies grafting experiments have revealed differences in the migration pathways of vagal NCC within different regions of the chick gut (Burns and Le Douarin, 1998), For example, when colonising the pre-umbilical intestine, the smooth muscle layers are undeveloped and migrating crest cells are randomly distributed within the mesenchyme. However, in the post-umbilical intestine the migration front of vagal NCC is located in the outermost layers of the mesenchyme, adjacent to the serosal epithelium. As the crest cells progress along the gut to reach the caecum, the circular muscle layer begins to develop, with the result that the migrating NCC encounter a different environment through which to migrate. Here, crest cells become orientated on either side of the circular muscle layers, in the regions corresponding to the presumptive myenteric and submucosal ganglia. A further change in migration pattern occurs in the colorectum. Vagal NCC initially colonise the submucosal region before migrating outwards through the circular muscle layer to populate the myenteric plexus region. Although the submucosal plexus is the first to be colonised by NCC, the myenteric plexus is the first to mature and express neuronal markers (Burns and Le Douarin, 1998). The reason for this difference in ENS colonisation is not clear, but interactions with nerve fibres derived from the nerve of Remak that penetrate the gut at the level of the myenteric plexus may be involved.
Unlike the colorectum in birds, in the intestine of avians and mammals, including humans, NCC initially colonise the myenteric plexus and the submucosal plexus arises from the secondary migration of cells within the myenteric region (Payette et al., 1984; Burns and Le Douarin, 1998; McKeown et al., 2001). Recent studies in the laboratory of Michael Gershon have implicated netrins in the guidance of these secondary migrations from the outer mesenchyme of the bowel towards the submucosa and into the pancreas (Jiang et al., 2003). These authors demonstrated that netrins (netrin-1 and netrin-3 in mice and netrin-2 in chicks) and the netrin receptors DCC (deleted in colorectal cancer), neogenin and the adenosine $\mathrm{A} 2 \mathrm{~b}$ receptor, are expressed in the fetal mucosa and pancreas and that crest-derived cells, expressing DCC, migrate towards netrin expressing cells and thus populate the presumptive submucosal plexus region.

In contrast to vagal cells, in the chick, sacral NCC initially coalesce in the dorsal aspect of the gut wall to form the nerve of Remak, then migrate into the outer layers of the gut, along axons that project from the Remak to the presumptive myenteric plexus region. These cells therefore initially colonise the outer layers of the gut wall and thereafter migrate inwards, through the circular muscle layer, to colonise the submucosal plexus region (Burns and Le Douarin, 1998). The study of Shepherd and Raper (Shepherd and Raper, 1999) provides an intriguing insight into the factors influencing the pattern of axon projections that may in turn account for the spatiotemporal colonisation of the hindgut by sacral NCC. These authors reported that early in development, prior to the outgrowth of axons into the hindgut, collapsin-1, a secreted glycoprotein that belongs to the Semaphorin family of molecules (Luo et al., 1993) and acts as an axon repellent (Behar et al., 1996, Messersmith et al., 1995, Puschel et al., 1995), is expressed throughout the wall of the hindgut. However, at E8, the expression of collapsin- 1 retreats from the outer muscle layers and becomes confined to the inner submucosal and mucosal regions. The removal of this inhibitory guidance cue may permit axons to project from the nerve of Remak into the gut, which in turn would facilitate entry of sacral NCC into the hindgut. Although collapsin-1 has been reported to be a repulsive signal for NCC migrating in both the hindbrain and trunk regions, where these cell populations express the collapsin-1 receptor, neuropilin-1 (Eickholt et al., 1999), the findings of Shepherd and Raper (Shepherd and Raper, 1999) suggest that collapsin-1 does not have a role in patterning vagal NCC in the hindgut, since at E6/E7 these cells are colonising caudal regions of the gut where collapsin-1 mRNA is present. However, it is not clear if collapsin-1 affects the patterning of sacral NCC directly, since it appears to inhibit growth of the axons along which they migrate to gain entry to the hindgut, rather than sacral NCC migration per se.

\section{Do vagal and sacral NCC have special properties which allow them to colonise the gut?}

The ENS is derived from cells that originate in two very specific regions of the neuraxis - the vagal and sacral neural crest. Why do NCC migrate to the gut from these particular sites? Is the environment favourable/permissive to gut colonisation at these locations, or do these crest cells have particular "homing" characteristics that allow them to find the gut? Extensive heterotopic transplantation studies performed in the laboratory of Nicole Le 

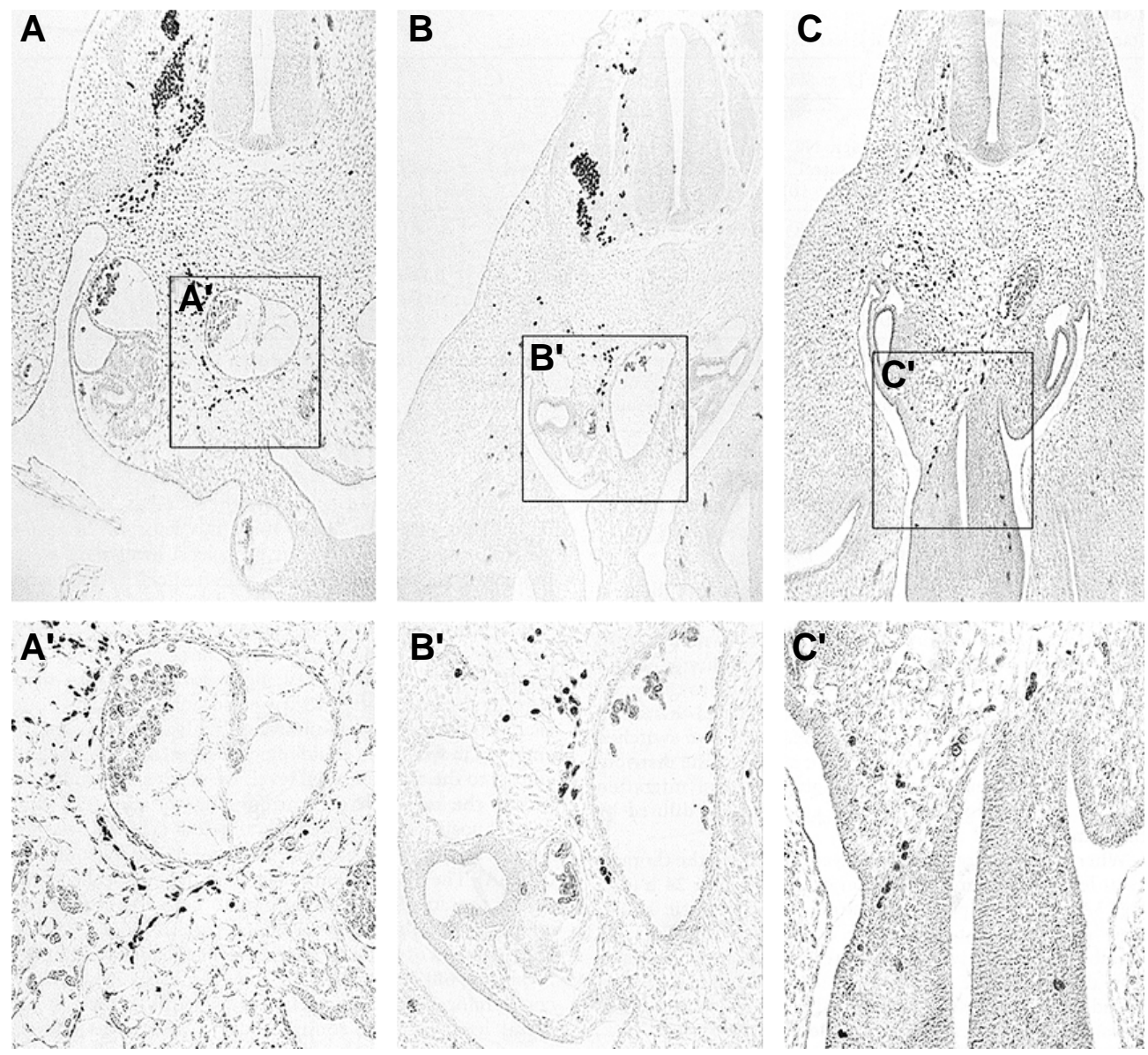

Fig. 1. Sections through chick hosts which received grafts of quail dorsal neural tubes and then were fixed $48 \mathrm{~h}$ later (at stage 22/23). Quail cells are identified with the QCPN antibody and appear black in these sections. (A, $\left.\mathbf{A}^{\prime}\right)$ Neural crest cells derived from a sacrallevel neural tube were grafted to the thoracic level. The boxed area shown at higher magnification in ( $\left.A^{\prime}\right)$ reveals that the cells migrate no farther than just ventral to the dorsal aorta. $\left(\mathbf{B}, \mathbf{B}^{\prime}\right)$ Similarly when thoracic-level neural crest cells are grafted to the thoracic level of a chick host, the grafted cells go no farther than the lateral edge of the dorsal aorta. In both instances, the grafted cells are coincident with the host neural crest cells. (C,C') However, thoracic-level quail neural crest cells do reach the gut mesenchyme if they are grafted to the sacral level. Reprinted from Dev. Biol., Vol 219, No 1, Erickson and Goins, "Sacral neural crest cell migration to the gut is dependent upon the migratory environment and not cell-autonomous migratory properties", pages 79-97, Copyright (2000), with permission from Elsevier.
Douarin have demonstrated that the fate of NCC depends more on signals encountered within the microenvironment along migration pathways, than on the axial level of origin (Le Douarin and Kalcheim, 1999). When fragments of neural primordial from quail were grafted into chick embryos, the NCC migrated to sites characteristic of their new axial level rather than their origin. For example, when vagal neural crest was replaced with trunk crest from a quail embryo, which normally gives rise to sensory and sympathetic ganglia, the grafted cells colonised the gut and gave rise to neurons that displayed appropriate cholinergic, peptidergic and monoaminergic enteric phenotypes (Fontaine-Perus et al., 1982, Le Douarin et al., 1975, Le Douarin and Teillet, 1974, Rothman etal., 1986). In addition, when cephalic and vagal neural crest was transplanted into the adrenomedullary axial level, adjacent to somites 18-24, these cells gave rise to adrenergic cells in sympathetic ganglia and to adrenal gland cells (Le Douarin and Teillet, 1974). Therefore, although there is no evidence to suggest that vagal and sacral NCC are committed to enteric phenotypes prior to migration, since they differentiate into sitespecific neuronal phenotypes when transplanted elsewhere along the neuraxis, it is still possible that these cells may have special migratory properties, or some level of prespecification, that allows them to colonise the gut and form the ENS. We tested this theory by utilising heterotopic interspecies grafting experiments where vagal neural crest obtained from E1.5 quail embryos was transplanted into the sacral region of E2.5 chick embryos. Transplanted vagal NCC were found to rapidly migrate into the gut and numerous cells were observed in the hindgut mesenchyme as early at E4. The colorectum was extensively colonised by E7 and by E10, the stage at which sacral NCC normally begin to enter the hindgut in large numbers, myenteric and submucosal ganglia were well formed by donor cells and the migration front had progressed into the pre-umbilical intestine (Burns et al., 2002). In contrast, sacral NCC, when transplanted to the vagal region of the neuraxis, also colonised the gut, but in much lower numbers than vagal cells, in a manner more akin to their colonisation of the hindgut. These findings demonstrate a cell autonomous difference in the migratory properties of the two NCC populations, with the rostral, vagal NCC being more invasive of the gut than the caudal, sacral NCC population. The reasons for the difference in invasive capacity between these two populations are still to be determined, but contributing factors may include changes in the expression of cell-signalling molecules involved in NCC migration/proliferation that occur during development. Alternatively, vagal NCC may be prespecified as ENS precursors, as originally suggested by Le Douarin and Teillet (Le Douarin and Teillet, 1974). This theory has been supported by studies that have demonstrated the ability of vagal NCC to reach the gut from different locations, such as those by Burns et al. (Burns et al., 2002) outlined above and earlier studies by Rothman et al. (Rothman et al., 1993). These latter authors demonstrated that when segments of embryonic gut containing vagal NCC were backtransplanted into the vagal and sacral regions of younger embryos, the vagal NCC remigrated and colonised the developing younger gut. 
Following the above evidence concerning the fate of vagal NCC transplanted to other regions of the neuraxis, heterotopic grafting experiments, performed in the lab of Carol Erickson, have tested the hypothesis that sacral NCC possess cell autonomous properties that allow them to colonise the gut. By transplanting sacral crest to the trunk region and vice versa, Erickson and Goins (Erickson and Goins, 2000) found that the crest cells behaved according to their new position, rather than their site of origin. Thus thoracic cells, when grafted to the sacral level, were initially distributed similarly to normal sacral cells and could also be found in the gut mesenchyme at later stages of development, while sacral cells, grafted to the thoracic level, did not reach the dorsal gut mesenchyme (Fig. 1). The authors interpreted these findings as providing evidence that:(i) sacral NCC have no cell autonomous properties that allow them to colonise the gut and (ii) at the sacral level the environment is sufficient to allow crest cells from other axial levels to enter the gut mesenchyme (Erickson and Goins, 2000).

What might confer pre-specification of vagal NCC towards an enteric fate? Premigratory vagal NCC have been shown to express RET (Robertson and Mason, 1995), which is essential for normal ENS development in mice and humans (Edery et al., 1994, Pasini et al., 1995, Romeo et al., 1994, Schuchardt et al., 1994) and may be involved in the pre-specification of vagal NCC to the enteric lineage. The importance of RET in ENS development is well documented (Taraviras etal., 1999; Manie etal., 2001) and studies performed in the laboratory of Vassilis Pachnis have demonstrated the role of RET-positive NCC as multipotential ENS progenitors. When RET + cells were isolated and injected in small numbers, or individually, into the stomach of aganglionic murine gastrointestinal tracts, then cultured for 7 days, enteric neurons and glia were subsequently found throughout the gut, thus highlighting the extensive migratory and proliferative capacity of RET+ vagal NCC (Natarajan et al., 1999). Although we have recently shown that RET is also expressed by sacral NCC (Burns et al., 2002), it is unclear whether other factors may account for the difference in invasive capacity of vagal and sacral NCC. Within the gut, undifferentiated NCC have been shown to be p75 NTR/RET/Phox2b/Sox10 immunopositive (Young et al., 2003; Young et al., 1999), therefore a complex set of overlapping signals may be required to confer an enteric lineage on crest cells. As development proceeds, the expression of signalling molecules appears to be modified in order to direct crest cells towards neuronal and glial phenotypes within the gut. For example, differentiating neurons subsequently exhibit high levels of RET, low p75 NTR and undetectable Sox10 immunostaining, whereas glial precursors are BFABP+/Sox $10+/ p 75^{\mathrm{NTR}}+$, with S100b and GFAP becoming detectable later in development (Young et al., 1999).

Therefore by taking all the above findings into account, the following tentative points emerge:- (i) vagal and sacral NCC are not committed solely to an ENS lineage, (ii) vagal cells (and perhaps sacral cells) may be pre-specified towards an ENS lineage, possibly due, at least in part, to the expression of the RET receptor, (iii) vagal NCC are endowed with a higher migratory and proliferative capacity than sacral cells and (iv) the environment at the vagal and sacral levels is permissive to gut colonisation by crest cells from all levels of the neuraxis.

\section{Unidirectional migration of vagal and sacral NCC during gut colonisation}

Vagal NCC colonise the gut in a single rostrocaudal wave of migration (Burns and Le Douarin, 1998, Young et al., 1998), with vagal cells reaching the level of the umbilicus in the chick at E5, the cecal region at $E 6$ and the colorectum at E7.5. The entire length of the chick gut is colonised by E8.5 (Burns and Le Douarin, 1998). In the mouse and human, the gut is colonised by vagal NCC at E14 (Young et al., 1998) and week 7 (Wallace and Burns, 2005) respectively. Sacral NCC colonise the gut in an opposing caudorostral direction; these cells initially form the nerve of Remak in the chick, then enter the hindgut, beginning at E7. Although sacral NCC are most numerous in the terminal region of the hindgut, they can be found along the entire post-umbilical gut. What drives these two crest cell populations in such directional fashions along the gut? One possible explanation is that of "population pressure" as a source of migratory drive, as proposed by (Hearn et al., 1998) for NCC in vitro. Under this model, vagal NCC would be forced to move away from their point of entry in the foregut, causing them to migrate towards the unpopulated caudal gut regions. However, it is unlikely that this could apply to sacral NCC, since these cells enter the gut when it is already extensively colonised by vagal cells, therefore there are no longer "unpopulated" regions to move into. A further argument countering the "population
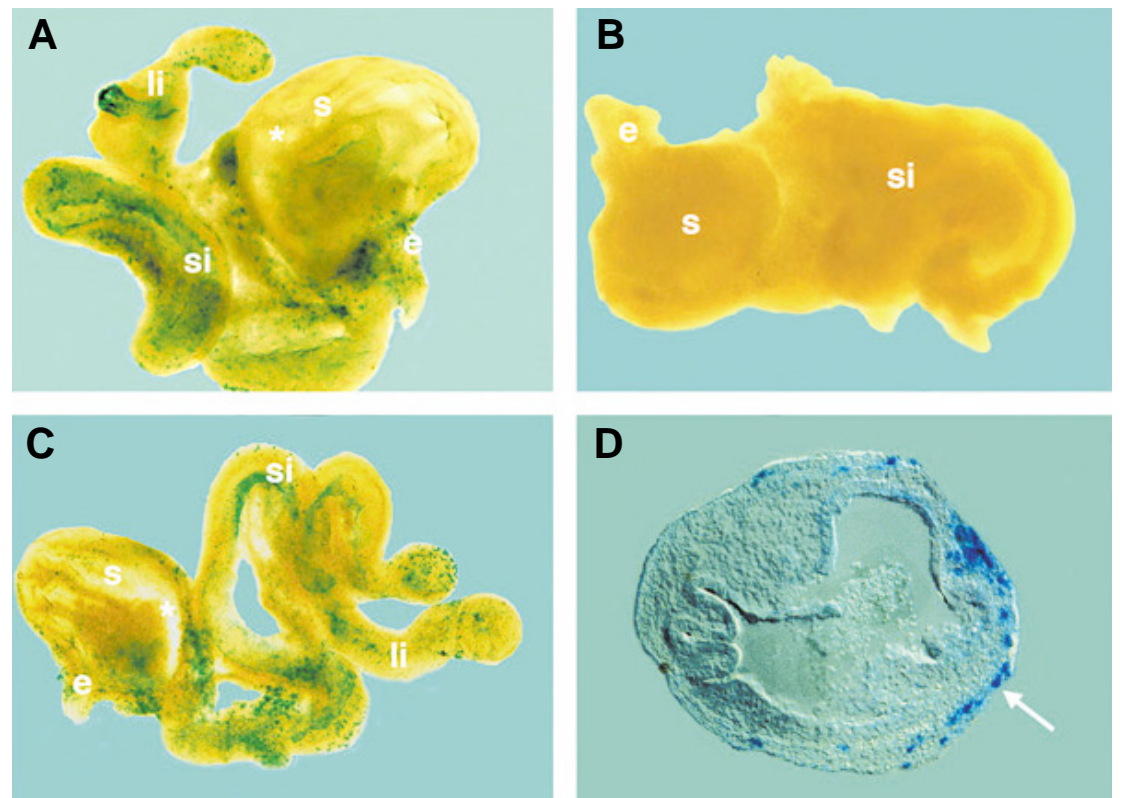

Fig. 2. RET+ cells from fetal gut can colonise wild-type or RET-deficient gut in organ culture. Immunoselected RET+ cells were injected into the stomach wall of E11.5 gut derived from +/Ret.k - (A) or Ret.k -/Ret.k - (C) mouse embryos. The site of injection into the stomach wall is indicated by an asterisk. A non-injected control gut is shown in (B). Sections of X-gal-stained guts revealed that the $\beta$-gal+ progeny of the RET+ cells (arrow) were localised at the periphery of the gut wall (D). Abbreviations: e, esophagus; li, large intestine; s, stomach; si, small intestine. Reproduced from Natarajan et al., (1999) Development 126, 157-168, with permission from The Company of Biologists Ltd. 

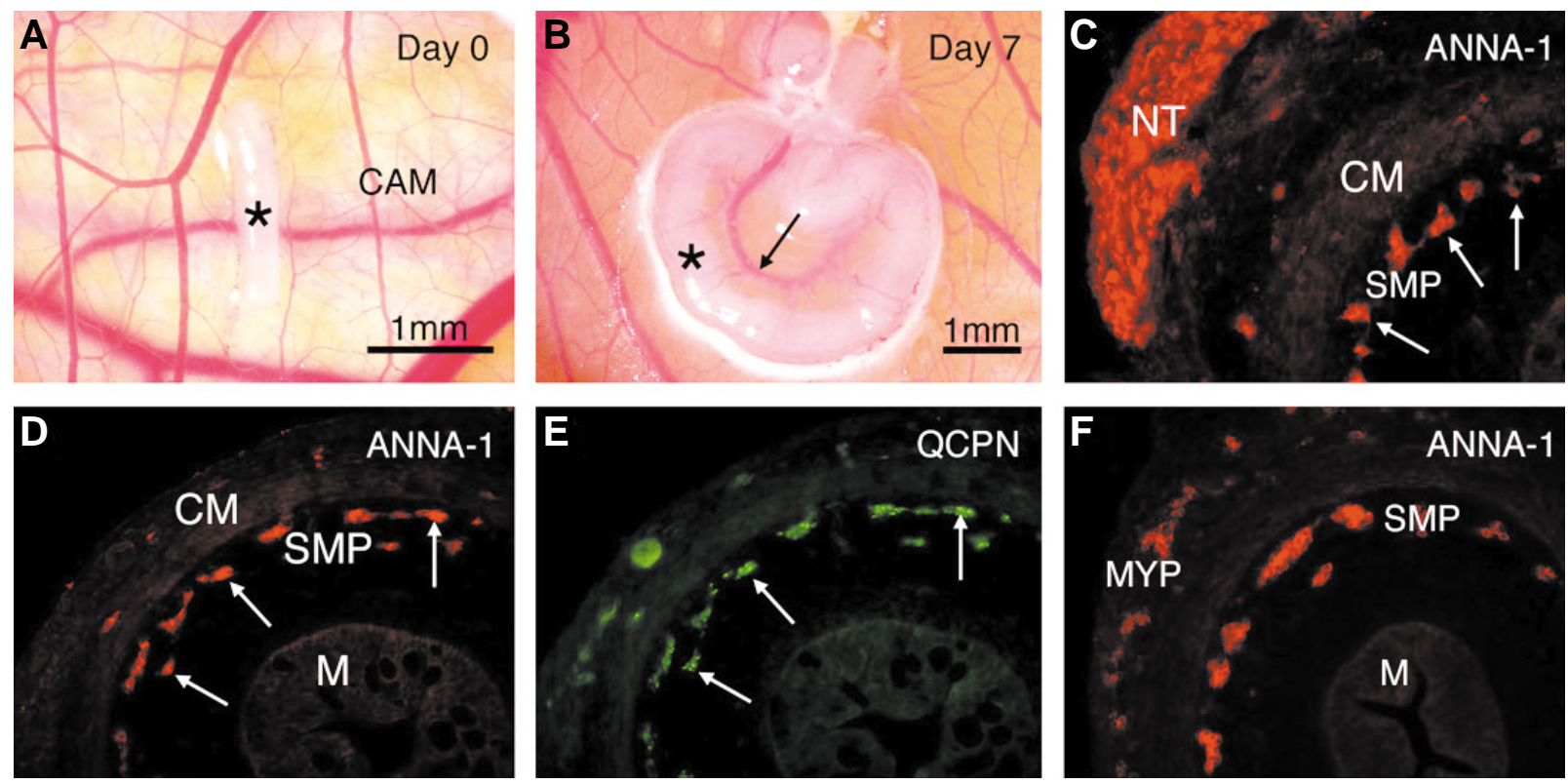

Fig. 3. Colonisation of aganglionic gut grown on the chick chorioallantoic membrane. (A) E6 chick hindgut $\left({ }^{*}\right)$ was placed on chick chorioallantoic membrane (CAM), that had been lightly scraped to encourage growth of blood vessels. (B) After 7 days on the CAM, the gut (*) increased dramatically in length and was supplied with a large blood vessel (arrow). (C) When quail neural tube (NT) and associated neural crest cells, was positioned adjacent to the aganglionic gut on the CAM and grown for 3 days, NCC from the neural tube migrated into the gut and became positioned in the submucosal plexus region (SMP, arrows), towards the inner aspect of the circular muscle layer (CM). (D,E) Cells within the sub-mucosal plexus that were immunopositive for the pan-neuronal marker ANNA-1 (D, arrows), were shown to be of quail origin using double labelling with the quail cell specific marker, OCPN (E, arrows). (F) After 5 days on the CAM, crest cells were present in the submucosal plexus (SMP) and myenteric plexus (MYP) regions. M, mucosa.

pressure" theory for gut colonisation comes from the work of Natarajan et al., (Natarajan et al., 1999) outlined above. In these studies, when small numbers, or even single RET+ vagal NCC were microinjected into the stomach of aganglionic gastrointestinal tracts, then grown in culture, individual cells were found to migrate extensively from the point of entry, either rostrocaudally along the gut, or caudorostrally into the esophagus (Fig. 2). In such cases, there was little or no population pressure driving the cells away from each other, so other mechanisms must account for their extensive migration

Undoubtedly cell-cell signalling mechanisms play a vital role in directing vagal NCC migration to and within the gut. The presence of diffusable chemoattractive molecules, that originate in the gut mesenchyme, have been demonstrated to play an important role in attracting crest cells. This idea is supported by the backtransplantation experiments outlined above (Rothman et al., 1993) and by experiments originally performed by Fontaine-Perus etal., (Fontaine-Perus etal., 1988) and more recently examined by Burns and Cooper (unpublished), using sensory (nodose) ganglia grafted into younger embryos or vagal neural crest cultured adjacent to aganglionic gut segments respectively. In these latter experiments, when sensory ganglia or vagal neural tube from quail embryos was placed adjacent to segments of aganglionic chick gut and either cultured or grown on the chick chorioallantoic membrane, NCC migrated into the gut and initially became positioned within the presumptive submucosal plexus before colonising the myenteric plexus (Fig. 3). Such studies provide strong evidence for the existence of chemoattractive interactions between the gut and NCC, since crest cells, derived from either the nodose ganglia or vagal neural tube, when exposed to signal(s) originating within aganglionic gut, migrated and differentiated into ENS cells. What is the nature of the signalling interactions that could drive such migratory processes? A strong candidate is the RET/GFR $\alpha / G D N F$ signalling pathway. Using organ-cultured gut and explants grown on collagen gel, Young etal.(Young etal., 2001) have demonstrated that GDNF, the ligand for the RET/GFR $\alpha$ receptor complex, is a chemoattractant for enteric neural cells that promotes outgrowth of axons and directed migration of vagal NCC along the gut. Although the mechanisms by which GDNF could influence the rostrocaudal migration of NCC is not clear, Young et al., postulated that GDNF protein levels could be higher in more caudal, uncolonised, areas that could act as GDNF "sinks". NCC could then be attracted towards these areas with higher levels of GDNF, in a gradientdependent manner. Further supporting evidence for this idea has come from the recent study of Natarajan et al., (Natarajan et al., 2002). These authors demonstrated an interaction between NCC and GDNF, as in their experiments crest cells within the fetal mouse small intestine were found to migrate towards an exogenous source of GDNF in a RET-dependent manner. They also showed that GDNF is expressed at high levels in regions of the gut preceding the migration front of rostrocaudally migrating vagal NCC. When vagal cells colonised the foregut, GDNF expression was high in the stomach and when present in the midgut, GDNF expression was upregulated in the more posteriorly located caecum, concordant with the theory of GDNF acting as chemoattractant centres for migrating NCC. However, subsequent upregulation of GDNF expression within the hindgut, ahead of migrating NCC, has not been described to date, thus it is possible that the mechanisms directing hindgut colonisation are distinct from those acting in the foregut and midgut. 
In addition to its chemoattractive role in ENS development outlined above, GDNF has also been reported to be necessary for the proliferation and survival of ENS precursors (Chalazonitis etal., 1998, Hearn et al., 1998, Heuckeroth et al., 1998), processes that may be modulated by endothelin-3 (EDN3) which has been shown to inhibit the differentiation of migrating NCC (Hearn et al., 1998); (Wu et al., 1999). This inhibition of crest cell differentiation may ensure that sufficient ENS precursors are available to completely colonise the gut. In spontaneous or targeted mutations affecting EDN3(Baynash et al., 1994, Bolande, 1975, Jacobs-Cohen et al., 1987), the distal hindgut fails to be colonised by NCC and remains aganglionic, supporting the theory that in the absence of EDN3, enteric precursors differentiate prematurely and therefore fail to colonise the entire length of the gut.

\section{Acknowledgements \\ $A J B$ was partly supported by a research grant from the Biotechnology and Biological Sciences Research Council (BBSRC). The author gratefully acknowledges Carol Erickson and Vassilis Pachnis for permission to include their published work in figures 1 and 2 respectively.}

\section{References}

ALLAN, I.J. and NEWGREEN, D.F. (1980). The origin and differentiation of enteric neurons of the intestine of the fowl embryo. Am J Anat 157: 137-54.

BAYNASH, A.G., HOSODA, K., GIAID, A., RICHARDSON, J.A., EMOTO, N., HAMMER, R.E. and YANAGISAWA, M. (1994). Interaction of endothelin-3 with endothelin-b receptor is essential for development of epidermal melanocytes and enteric neurons. Cel/79: 1277-85.

BEHAR, O., GOLDEN, J.A., MASHIMO, H., SCHOEN, F.J. and FISHMAN, M.C. (1996). Semaphorin iii is needed for normal patterning and growth of nerves, bones and heart. Nature 383: 525-8.

BOLANDE, R.P. (1975). Hirschsprung's disease, aganglionic or hypoganglionic megacolon. Animal model: Aganglionic megacolon in piebald and spotted mutant mouse strains. Am J Patho/79: 189-92.

BURNS, A.J., CHAMPEVAL, D. and LE DOUARIN, N.M. (2000). Sacral neural crest cells colonise aganglionic hindgut in vivo but fail to compensate for lack of enteric ganglia. Dev Bio/219: 30-43.

BURNS, A.J., DELALANDE, J.M. and LE DOUARIN, N.M. (2002). In ovo transplantation of enteric nervous system precursors from vagal to sacral neural crest results in extensive hindgut colonisation. Development 129: 2785-96.

BURNS, A.J. and LE DOUARIN, N.M. (1998). The sacral neural crest contributes neurons and glia to the post- umbilical gut: Spatiotemporal analysis of the development of the enteric nervous system. Development 125: 4335-47.

BURNS, A.J. and LE DOUARIN, N.M. (2001). Enteric nervous system development: Analysis of the selective developmental potentialities of vagal and sacral neural crest cells using quail-chick chimeras. Anat Rec 262: 16-28.

CHALAZONITIS, A., ROTHMAN, T.P., CHEN, J. and GERSHON, M.D. (1998). Agedependent differences in the effects of gdnf and nt-3 on the development of neurons and glia from neural crest-derived precursors immunoselected from the fetal rat gut: Expression of gfralpha-1 in vitro and in vivo. Dev Bio/204: 385-406.

COSTA, M., BROOKES, S.J. and HENNIG, G.W. (2000). Anatomy and physiology of the enteric nervous system. Gut47 Suppl 4: iv15-9; discussion iv26.

DURBEC, P.L., LARSSON-BLOMBERG, L.B., SCHUCHARDT, A., COSTANTINI, F. and PACHNIS, V. (1996). Common origin and developmental dependence on c-ret of subsets of enteric and sympathetic neuroblasts. Development 122: 349-58.

EDERY, P., LYONNET, S., MULLIGAN, L.M., PELET, A., DOW, E., ABEL, L., HOLDER, S., NIHOUL-FEKETE, C., PONDER, B.A. and MUNNICH, A. (1994). Mutations of the ret proto-oncogene in hirschsprung's disease. Nature 367: 378-80.

EICKHOLT, B.J., MACKENZIE, S.L., GRAHAM, A., WALSH, F.S. and DOHERTY, P. (1999). Evidence for collapsin-1 functioning in the control of neural crest migration in both trunk and hindbrain regions. Development 126: 2181-9.
EPSTEIN, M.L., MIKAWA, T., BROWN, A.M. and MCFARLIN, D.R. (1994). Mapping the origin of the avian enteric nervous system with a retroviral marker. Dev Dyn 201: 236-44.

ERICKSON, C.A. and GOINS, T.L. (2000). Sacral neural crest cell migration to the gut is dependent upon the migratory environment and not cell-autonomous migratory properties. Dev Bio/219: 79-97.

FONTAINE-PERUS, J., CHANCONIE, M. and LE DOUARIN, N.M. (1988). Developmental potentialities in the nonneuronal population of quail sensory ganglia. Dev Bio/128: 359-75.

FONTAINE-PERUS, J.C., CHANCONIE, M. and LE DOUARIN, N.M. (1982). Differentiation of peptidergic neurones in quail-chick chimaeric embryos. Cell Differ 11: 183-93.

FURNESS, J.B. (2000). Types of neurons in the enteric nervous system. J Auton Nerv Syst 81: 87-96.

FURNESS, J.B. and COSTA, M. (1987). The enteric nervous system. Churchill Livingstone, Edinburgh.

HEARN, C.J., MURPHY, M. and NEWGREEN, D. (1998). Gdnf and et-3 differentially modulate the numbers of avian enteric neural crest cells and enteric neurons in vitro. Dev Bio/197: 93-105.

HEUCKEROTH, R.O., LAMPE, P.A., JOHNSON, E.M. and MILBRANDT, J. (1998). Neurturin and gdnf promote proliferation and survival of enteric neuron and glial progenitors in vitro. Dev Bio/200: 116-29.

JACOBS-COHEN, R.J., PAYETTE, R.F., GERSHON, M.D. and ROTHMAN, T.P. (1987). Inability of neural crest cells to colonize the presumptive aganglionic bowel of Is/ls mutant mice: Requirement for a permissive microenvironment. $J$ Comp Neuro/255: 425-38.

JIANG, Y., LIU, M.T. and GERSHON, M.D. (2003). Netrins and DCC in the guidance of migrating neural crest-derived cells in the developing bowel and pancreas. Dev Bio/258: 364-84.

KAPUR, R.P. (2000). Colonization of the murine hindgut by sacral crest-derived neural precursors: Experimental support for an evolutionarily conserved model. Dev Bio/227: 146-55.

KAPUR, R.P., YOST, C. and PALMITER, R.D. (1992). A transgenic model for studying development of the enteric nervous system in normal and aganglionic mice. Development 116: 167-75.

LE DOUARIN, N.M. (1969). Particularities du noyau interphasique chez la caille japonaise (coturnix coturnix japonica). Utilisation de ces particularites comme "marquage biologique" dans des recherches sur les interactions tissulaires et les migrations cellulaires au cours de l'ontogenese. Bull. Biol. France Belg. 103: 435-452.

LE DOUARIN, N.M. and KALCHEIM, C. (1999). The neural crest. Cambridge University Press, Cambridge.

LE DOUARIN, N.M., RENAUD, D., TEILLET, M.A. and LE DOUARIN, G.H. (1975). Cholinergic differentiation of presumptive adrenergic neuroblasts in interspecific chimeras after heterotopic transplantations. Proc Nat/ Acad Sci USA 72: 728-32.

LE DOUARIN, N.M. and TEILLET, M.A. (1973). The migration of neural crest cells to the wall of the digestive tract in avian embryo. J Embryol Exp Morpho/30: 31-48.

LE DOUARIN, N.M. and TEILLET, M.A. (1974). Experimental analysis of the migration and differentiation of neuroblasts of the autonomic nervous system and of neurectodermal mesenchymal derivatives, using a biological cell marking technique. Dev Bio/41: 162-84.

LUO, Y., RAIBLE, D. and RAPER, J.A. (1993). Collapsin: A protein in brain that induces the collapse and paralysis of neuronal growth cones. Cel/75: 217-27.

MANIE, S., SANTORO, M., FUSCO, A. and BILLAUD, M. (2001). The ret receptor: Function in development and dysfunction in congenital malformation. Trends Genet 17: 580-9.

McKEOWN, S.J., CHOW, C.W. and YOUNG, H.M. (2001). Development of the submucous plexus in the large intestine of the mouse. Cell Tissue Res 303: 301-5.

MEIJERS, J.H., TIBBOEL, D., VAN DER KAMP, A.W., VAN HAPEREN-HEUTS, I.C. and MOLENAAR, J.C. (1989). A model for aganglionosis in the chicken embryo. J Pediatr Surg 24: 557-61.

MESSERSMITH, E.K., LEONARDO, E.D., SHATZ, C.J., TESSIER-LAVIGNE, M., GOODMAN, C.S. and KOLODKIN, A.L. (1995). Semaphorin iii can function as a selective chemorepellent to pattern sensory projections in the spinal cord. Neuron 14: 949-59. 
NATARAJAN, D., GRIGORIOU, M., MARCOS-GUTIERREZ, C.V., ATKINS, C. and PACHNIS, V. (1999). Multipotential progenitors of the mammalian enteric nervous system capable of colonising aganglionic bowel in organ culture. Development 126 : 157-68.

NATARAJAN, D., MARCOS-GUTIERREZ, C., PACHNIS, V. and DE GRAAFF, E. (2002). Requirement of signalling by receptor tyrosine kinase ret for the directed migration of enteric nervous system progenitor cells during mammalian embryogenesis. Development 129: 5151-60.

NISHIJIMA, E., MEIJERS, J.H., TIBBOEL, D., LUIDER, T.M., PETERS-VAN DER SANDEN, M.M., VAN DER KAMP, A.W. and MOLENAAR, J.C. (1990). Formation and malformation of the enteric nervous system in mice: An organ culture study. $J$ Pediatr Surg 25: 627-31.

PASINI, B., BORRELLO, M.G., GRECO, A., BONGARZONE, I., LUO, Y., MONDELLINI, P., ALBERTI, L., MIRANDA, C., ARIGHI, E., BOCCIARDI, R. et al. (1995). Loss of function effect of ret mutations causing hirschsprung disease. Nat Genet 10:35-40.

PAYETTE, R.F., BENNETT, G.S. and GERSHON, M.D. (1984). Neurofilament expression in vagal neural crest-derived precursors of enteric neurons. Dev Biol 105: 273-87.

POMERANZ, H.D. and GERSHON, M.D. (1990). Colonization of the avian hindgut by cells derived from the sacral neural crest. Dev Bio/137: 378-94.

POMERANZ, H.D., ROTHMAN, T.P. and GERSHON, M.D. (1991). Colonization of the post-umbilical bowel by cells derived from the sacral neural crest: Direct tracing of cell migration using an intercalating probe and a replication-deficient retrovirus. Development 111: 647-55.

PUSCHEL, A.W., ADAMS, R.H. and BETZ, H. (1995). Murine semaphorin d/collapsin is a member of a diverse gene family and creates domains inhibitory for axonal extension. Neuron 14: 941-8.

ROBERTSON, K. and MASON, I. (1995). Expression of ret in the chicken embryo suggests roles in regionalisation of the vagal neural tube and somites and in development of multiple neural crest and placodal lineages. Mech Dev53: 329-44.

ROMEO, G., RONCHETTO, P., LUO, Y., BARONE, V., SERI, M., CECCHERINI, I., PASINI, B., BOCCIARDI, R., LERONE, M., KAARIAINEN, H. et al. (1994). Point mutations affecting the tyrosine kinase domain of the ret proto-oncogene in hirschsprung's disease. Nature 367: 377-8.

ROTHMAN, T.P., LEDOUARIN, N.M., FONTAINE-PERUS, J.C. and GERSHON, M.D. (1993). Colonization of the bowel by neural crest-derived cells re-migrating from foregut backtransplanted to vagal or sacral regions of host embryos. Dev Dyn 196: 217-33.

ROTHMAN, T.P., SHERMAN, D., COCHARD, P. and GERSHON, M.D. (1986). Development of the monoaminergic innervation of the avian gut: Transient and permanent expression of phenotypic markers. Dev Bio/116: 357-80.
SCHUCHARDT, A., D'AGATI, V., LARSSON-BLOMBERG, L., COSTANTINI, F. and PACHNIS, V. (1994). Defects in the kidney and enteric nervous system of mice lacking the tyrosine kinase receptor ret. Nature 367: 380-3.

SERBEDZIJA, G.N., BURGAN, S., FRASER, S.E. and BRONNER-FRASER, M. (1991). Vital dye labelling demonstrates a sacral neural crest contribution to the enteric nervous system of chick and mouse embryos. Development 111: 85766.

SHEPHERD, I.T. and RAPER, J.A. (1999). Collapsin-1/semaphorin d is a repellent for chick ganglion of remak axons. Dev Bio/212: 42-53.

TARAVIRAS, S., MARCOS-GUTIERREZ, C.V., DURBEC, P., JANI, H., GRIGORIOU, M., SUKUMARAN, M., WANG, L.C., HYNES, M., RAISMAN, G. and PACHNIS, V. (1999). Signalling by the ret receptor tyrosine kinase and its role in the development of the mammalian enteric nervous system. Development 126: 2785-97.

VINCENT, M. and THIERY, J.P. (1984). A cell surface marker for neural crest and placodal cells: Further evolution in peripheral and central nervous system. Dev Biol103: 468-81.

WALLACE, A.S. and BURNS, A.J. (2005). Development of the enteric nervous system, smooth muscle and interstitial cells of Cajal in the human gastrointestinal tract. Cell Tissue Res. 319: 367-382.

WU, J.J., CHEN, J.X., ROTHMAN, T.P. and GERSHON, M.D. (1999). Inhibition of in vitro enteric neuronal development by endothelin-3: Mediation by endothelin b receptors. Development 126: 1161-73.

YNTEMA, C.L. and HAMMOND, W.S. (1954). The origin of intrinsic ganglia of trunk viscera from vagal neural crest in the chick embryo. J Comp Neuro/101: 515541.

YOUNG, H.M., BERGNER, A.J. and MULLER, T. (2003). Acquisition of neuronal and glial markers by neural crest-derived cells in the mouse intestine. J Comp Neuro/456: 1-11.

YOUNG, H.M., CIAMPOLI, D., HSUAN, J. and CANTY, A.J. (1999). Expression of ret-, p75(ntr)-, phox2a-, phox2b- and tyrosine hydroxylase-immunoreactivity by undifferentiated neural crest-derived cells and different classes of enteric neurons in the embryonic mouse gut. Dev Dyn216: 137-52.

YOUNG, H.M., HEARN, C.J., CIAMPOLI, D., SOUTHWELL, B.R., BRUNET, J.F. and NEWGREEN, D.F. (1998). A single rostrocaudal colonization of the rodent intestine by enteric neuron precursors is revealed by the expression of phox $2 \mathrm{~b}$, ret and $\mathrm{p} 75$ and by explants grown under the kidney capsule or in organ culture. Dev Bio/202: 67-84.

YOUNG, H.M., HEARN, C.J., FARLIE, P.G., CANTY, A.J., THOMAS, P.Q. and NEWGREEN, D.F. (2001). Gdnf is a chemoattractant for enteric neural cells. Dev Biol229: 503-16. 